\title{
Erratum to: The attractive recombinant phytase from Bacillus licheniformis: biochemical and molecular characterization
}

\author{
Mohamed Ali Borgi • Mouna Khila • Samira Boudebbouze • \\ Nushin Aghajari • Florette Szukala • Nicolas Pons • \\ Emmanuelle Maguin $\cdot$ Moez Rhimi
}

Published online: 31 May 2014

(C) Springer-Verlag Berlin Heidelberg 2014

Erratum to: Appl Microbiol Biotechnol (2013)

DOI 10.1007/s00253-013-5421-9

The original publication of this article inadvertently contained mistake. There is a change in authorship and the correct presentation is given above as well as it's corresponding affiliation below.

The online version of the original article can be found at http://dx.doi.org/ 10.1007/s00253-013-5421-9.

M. A. Borgi $\cdot$ M. Khila

Faculty of Sciences of Gafsa-Unit of Macromolecular Biochemistry and Genetic, Department of Life Sciences, Zarroug, 2112,

Gafsa, Tunisia

S. Boudebbouze $\cdot$ F. Szukala $\cdot$ N. Pons $\cdot$ E. Maguin $\cdot$ M. Rhimi $(\square)$

INRA, UMR 1319 Micalis, 78350 Jouy-en-Josas, France

e-mail: moez.rhimi@jouy.inra.fr

\section{N. Aghajari}

Laboratory for Biocrystallography and Structural Biology of

Therapeutical Targets, BMSSI-Institut de Biologie et Chimie des

Protéines, UMR 5086-CNRS/Université de Lyon, FR3302

"BioSciences Gerland-Lyon Sud", 7 Passage du Vercors,

69367 Lyon cedex 07, France 